\title{
Prognostic effect of preoperative red cell distribution width on the survival of patients who have undergone surgery for non-small cell lung cancer
}

\author{
HIROSHI MATSUI, YOHEI TANIGUCHI, NATSUMI MARU, TAKAHIRO UTSUMI, \\ TOMOHITO SAITO, HARUAKI HINO and TOMOHIRO MURAKAWA \\ Department of Thoracic Surgery, Kansai Medical University, Hirakata, Osaka 573-1010, Japan
}

Received August 26, 2020; Accepted March 1, 2021

DOI: $10.3892 / \mathrm{mco} .2021 .2270$

\begin{abstract}
Red cell distribution width (RDW) is a prognostic factor for various malignancies, including colorectal, breast and lung cancer. The effect of preoperative RDW on the prognosis of patients who have undergone surgery for non-small cell lung cancer (NSCLC) was investigated in the present study. This retrospective, single-institution study included consecutive patients who had undergone complete NSCLC resection between January 2006 and December 2013 at the Department of Thoracic Surgery of Kansai Medical University Hospital (Hirakata, Japan). The overall and recurrence-free survival rates were compared using univariate and multivariate Cox proportional hazard models. A stepwise backward elimination method with a probability level of 0.15 was performed to select the most powerful outcome predictor sets. A total of 338 cases with NSCLC were analyzed. Of these, 25 had high RDWs ( $\geq 50 \mathrm{fl}$ ) and 313 had low RDWs ( $<50 \mathrm{fl})$. The 5-year overall survival rates in patients with high and low RDWs were 0.40 [95\% confidence interval (CI): 0.21-0.58] and 0.80 (95\% CI: 0.76-0.84), respectively, and the recurrence-free survival rates were 0.48 (95\% CI: 0.25-0.68) and 0.70 (95\% CI: 0.64-0.75), respectively. High RDW was identified as an independent prognostic factor for overall survival [hazard ratio $(\mathrm{HR})=2.29$; $95 \%$ CI: $1.3-4.01$; $\mathrm{P}=0.004)$ but not for recurrence-free survival $(\mathrm{HR}=1.70 ; 95 \% \mathrm{CI}$ : 0.93-3.12; $\mathrm{P}=0.085$ ) by univariate and multivariate analysis. A high preoperative RDW was an independent predictor of poor prognosis in patients who had undergone radical resection of NSCLC. Therefore, patients with high RDW should be carefully monitored postoperatively, regardless of the disease stage.
\end{abstract}

Correspondence to: Professor Tomohiro Murakawa, Department of Thoracic Surgery, Kansai Medical University, 2-5-1 Shin-machi, Hirakata, Osaka 573-1010, Japan

E-mail: murakawa-tky@umin.ac.jp

Abbreviations: BMI, body mass index; NSCLC, non-small cell lung cancer; RDW, red cell distribution width

Key words: prognostic factor, red cell distribution width, non-small cell lung cancer, surgery, cachexia

\section{Introduction}

Red blood cell distribution width (RDW) is expressed as the ratio of the standard deviation of red blood cell volume and mean corpuscular volume, and is determined from the width of the erythrocyte volume distribution curve at a level of $20 \%$ above the baseline (1). RDW is an easily acquired and cost-effective parameter that is often measured as part of the complete blood count, and it reflects red blood cell volume heterogeneity, which may be attributable to the presence of small and large red blood cells. RDW is generally used together with mean corpuscular volume to diagnose and distinguish between different types of anemia (2). High RDW levels may be found in iron deficiency and megaloblastic anemia.

It was recently reported that RDW may be a poor prognostic factor in heart failure, sepsis and sarcoidosis (3-5). High RDW has also been associated with poor prognosis in several malignancies, such as colon, breast and esophageal cancer (6-8). The treatment options and prognosis assessment for malignant tumors are mainly based on the TNM stage, which has certain limitations, as patients with early-stage cancer may have a poor prognosis. Although the mechanisms underlying increased RDW remain unclear, several factors, including inflammation and malnutrition, may be involved. Few studies have reported an association between preoperative RDW levels and the long-term prognosis of patients with non-small cell lung cancer (NSCLC) to date. Historically, the standard surgical strategy for NSCLC has been lobectomy, although previous studies have also included cases of sublobar resection, the curability of which remains debatable $(9,10)$.

The aim of the present study was to investigate the prognostic impact of preoperative levels of RDW on the long-term survival of patients who have undergone radical surgery for NSCLC.

\section{Patients and methods}

Patient selection. Between January 2006 and December 2013, a total of 338 patients with lung cancer who had undergone anatomical resection (lobectomy or pneumonectomy) at the Department of Thoracic Surgery of Kansai Medical University Hospital (Hirakata, Japan) were retrospectively analyzed. 
Patients with sublobar resection (segmentectomy or wedge resection), serious coexistent infections, small cell carcinoma, $\mathrm{cN} 3$ or cM1 were excluded. The clinical records of all patients were reviewed.

Diagnosis and follow-up. The diagnosis of lung cancer was confirmed by bronchoscopic biopsy, computed tomography (CT)-guided biopsy or surgical specimen examination. Clinical and pathological staging was based on the 8th edition of the TNM classification of the Union for International Cancer Control (11). Tumor histological classification was based on the World Health Organization classification system (12). The interval between follow-ups was 3 months for the first 2 years, and 6 months thereafter for up to 5 years. A full examination and chest X-ray were performed at each visit, and a CT scan was performed annually. Other investigations, such as brain magnetic resonance imaging and/or positron emission tomography, were performed when clinically indicated.

Data collection and analysis. Laboratory samples and clinicopathological data, including age at surgery, sex, body mass index (BMI), Brinkman index, history of diabetes mellitus, heart diseases, other malignancies, Charlson Comorbidity Index, percent vital capacity (\%VC), percent forced expiratory volume in $1 \mathrm{sec}$ (FEV1.0\%), maximum standardized uptake value (SUVmax) and clinical TNM stage, were collected prior to surgery. The complete blood cell count and carcinoembryonic antigen (CEA) level were measured using two automatic analyzers (Sysmex XE-2100, Sysmex Corporation; AU5400 Chemistry System, Beckman Coulter, Inc.).

The normal range for RDW in our institution was $\geq 38$ and $<50 \mathrm{fl}$, and patients were divided into two groups, the high (RDW $\geq 50 \mathrm{fl}, \mathrm{n}=25$ ) and low (RDW $<50 \mathrm{fl}, \mathrm{n}=313$ ) RDW groups. The following categorical variables were compared between the high and low RDW groups: Age $(<68 / \geq 68)$, sex (male/female), BMI ( $\leq 23 />23)$, Brinkman index $(<400 / \geq 400)$, anemia (absent/present), CEA $(\leq 5 />5)$, diabetes mellitus (absent/present), heart disease (absent/present), past history of malignancy (absent/present), Charlson Comorbidity Index $(0-1 / 2+)$, \%VC $(\geq 80 /<80)$, FEV1.0\% ( $\geq 70 /<70)$, SUVmax $(<4.4 / \geq 4.4)$, clinical TNM stage (I, II or III) and pathological subtype (adenocarcinoma, squamous cell carcinoma or other types of carcinoma). The cutoff values of age, BMI, Brinkman index and SUVmax were set as 68 years, $23 \mathrm{~kg} / \mathrm{m}^{2}, 400$ and 4.4 , respectively, which were the median values of each variable. The cutoff values of anemia, CEA, \%VC and FEV1.0\% were determined by the normal range. The normal ranges of hemoglobin concentrations in our institution are 12.9-17.2 g/dl in male patients and $11.3-15.4 \mathrm{~g} / \mathrm{dl}$ in female patients. Survival outcomes, including overall and recurrence-free survival rates, were compared.

Statistical analysis. The $\chi^{2}$ and Fisher's exact tests were used to compare categorical covariates between the groups. The survival curves were constructed using the Kaplan-Meier method, and the differences between the groups were compared using the log-rank test. The prognostic factors of overall and recurrence-free survival were also compared between groups using the univariate and multivariate Cox proportional hazard model. A stepwise backward elimination method with a probability level of 0.15 was used to select the most powerful sets of outcome predictors.

All statistical analyses were performed using the statistical software packages Stata/SE 14.2 (StataCorp LP) and EZR (Saitama Medical Center, Jichi Medical University), which is a graphical user interface for R (The R Foundation for Statistical Computing) (13). For all analyses, $\mathrm{P}<0.05$ was considered to indicate a statistically significant difference.

\section{Results}

Clinicopathological characteristics. The present study included 338 patients ( 25 with a high RDW and 313 with a low RDW), 100 of whom succumbed to the disease (15 in the high RDW and 85 in the low RDW group) and 110 presented with recurrence (12 in the high RDW and 98 in the low RDW group). The baseline characteristics of all eligible cases $(n=338)$ are summarized in Table I.

Survival. High RDW (RDW $\geq 50 \mathrm{fl}$ ) was more common in male patients, patients without diabetes mellitus and patients with chronic obstructive pulmonary disease (Table I). The low RDW group exhibited higher overall and recurrence-free survival rates compared with the high RDW group $(\mathrm{P}=0.0001$ and 0.0266, respectively; Fig. 1A and B). Anemia was detected in 39 patients, including 2, 34 and 3 patients with microcytic, normocytic and macrocytic anemia, respectively. The 5-year overall survival rates for the high and low RDW groups were $0.40 \%$ (95\% CI: $0.21-0.58$ ) and $0.80 \%$ (95\% CI: 0.76-0.84), respectively, and the recurrence-free survival rates were 0.48\% (95\% CI: 0.25-0.68) and 0.70\% (95\% CI: 0.64-0.75), respectively.

Univariate and multivariate analysis of postoperative survival in lung cancer. Univariate analysis of overall survival revealed that RDW, age, sex, CEA, heart disease, history of malignancy, Charlson Comorbidity Index, \%VC, SUVmax, cTNM and pathological subtype were significant predictors (Table IIA). Multivariate analysis revealed that RDW, CEA, Charlson Comorbidity Index, SUVmax and cTNM were independent prognostic factors for overall survival (Table IIB). Univariate analysis of recurrence-free survival revealed that RDW, CEA, SUVmax and cTNM were significant predictors (Table IIIA). Multivariate analysis revealed that CEA, SUVmax and cTNM were independent prognostic factors for recurrence-free survival (Table IIIB).

\section{Discussion}

The present study identified high RDW as an independent prognostic factor for overall survival in patients with complete resection of NSCLC, irrespective of age. RDW is a measure of variability in the size of circulating erythrocytes, and is usually examined as part of complete blood count using an automatic measurement system.

RDW is used to differentiate the etiology of anemia, and it is easy to measure and cost-effective. In addition to the conventional use of RDW, elevated RDW is considered to be associated with chronic inflammation and poor nutritional status (14). Inflammation prevents erythrocyte maturation by 
Table I. Patient characteristics according to the RDW groups.

\begin{tabular}{|c|c|c|c|}
\hline \multirow{2}{*}{$\begin{array}{l}\text { Variables } \\
\text { (patient no. evaluated per variable) }\end{array}$} & \multicolumn{2}{|c|}{ RDW (fl) } & \multirow[b]{2}{*}{ P-value } \\
\hline & $<50$ & $\geq 50$ & \\
\hline Age, years (338) & & & 0.859 \\
\hline$<68$ & 156 & 12 & \\
\hline$\geq 68$ & 157 & 13 & \\
\hline $\operatorname{Sex}(338)$ & & & $0.03^{\mathrm{a}}$ \\
\hline Male & 191 & 21 & \\
\hline Female & 122 & 4 & \\
\hline Body mass index, $\mathrm{kg} / \mathrm{m}^{2}(338)$ & & & 0.328 \\
\hline$\leq 23$ & 156 & 15 & \\
\hline$>23$ & 157 & 10 & \\
\hline Brinkman index & & & 0.349 \\
\hline$<400$ & 143 & 9 & \\
\hline$\geq 400$ & 170 & 16 & \\
\hline Anemia (338) & & & 0.053 \\
\hline Absent & 280 & 19 & \\
\hline Present & 33 & 6 & \\
\hline Carcinoembryonic antigen, ng/ml (326) & & & 0.428 \\
\hline$\leq 5$ & 212 & 15 & \\
\hline$>5$ & 101 & 10 & \\
\hline Diabetes mellitus (338) & & & $0.02^{\mathrm{a}}$ \\
\hline Absent & 260 & 25 & \\
\hline Present & 53 & 0 & \\
\hline Heart disease (338) & & & $0.694^{\mathrm{a}}$ \\
\hline Absent & 291 & 23 & \\
\hline Present & 22 & 2 & \\
\hline History of malignancy (338) & & & $1^{\mathrm{a}}$ \\
\hline Absent & 260 & 21 & \\
\hline Present & 53 & 4 & \\
\hline Charlson Comorbidity Index (338) & & & 0.282 \\
\hline $0-1$ & 56 & 7 & \\
\hline $2+$ & 257 & 18 & \\
\hline$\% \mathrm{VC}(336)$ & & & $0.137^{\mathrm{a}}$ \\
\hline$\geq 80$ & 306 & 23 & \\
\hline$<80$ & 7 & 2 & \\
\hline FEV1.0\% (338) & & & 0.019 \\
\hline$\geq 70$ & 241 & 14 & \\
\hline$<70$ & 72 & 11 & \\
\hline SUVmax (246) & & & 0.098 \\
\hline$<4.4$ & 114 & 5 & \\
\hline$\geq 4.4$ & 199 & 20 & \\
\hline cTNM (338) & & & $0.559^{\mathrm{a}}$ \\
\hline $\mathrm{I}$ & 269 & 20 & \\
\hline II & 39 & 5 & \\
\hline III & 5 & 0 & \\
\hline Pathological subtype (338) & & & 0.116 \\
\hline Adenocarcinoma & 244 & 15 & \\
\hline Squamous cell carcinoma & 38 & 5 & \\
\hline Others & 31 & 5 & \\
\hline
\end{tabular}

aFisher's exact test. The $\chi^{2}$ or Fisher's exact tests were used for categorical covariates. RDW, red blood cell distribution width; VC, vital capacity; FEV1.0, forced expiratory volume in $1 \mathrm{sec}$; SUVmax, maximum standardized uptake value; cTNM, clinical TNM stage.
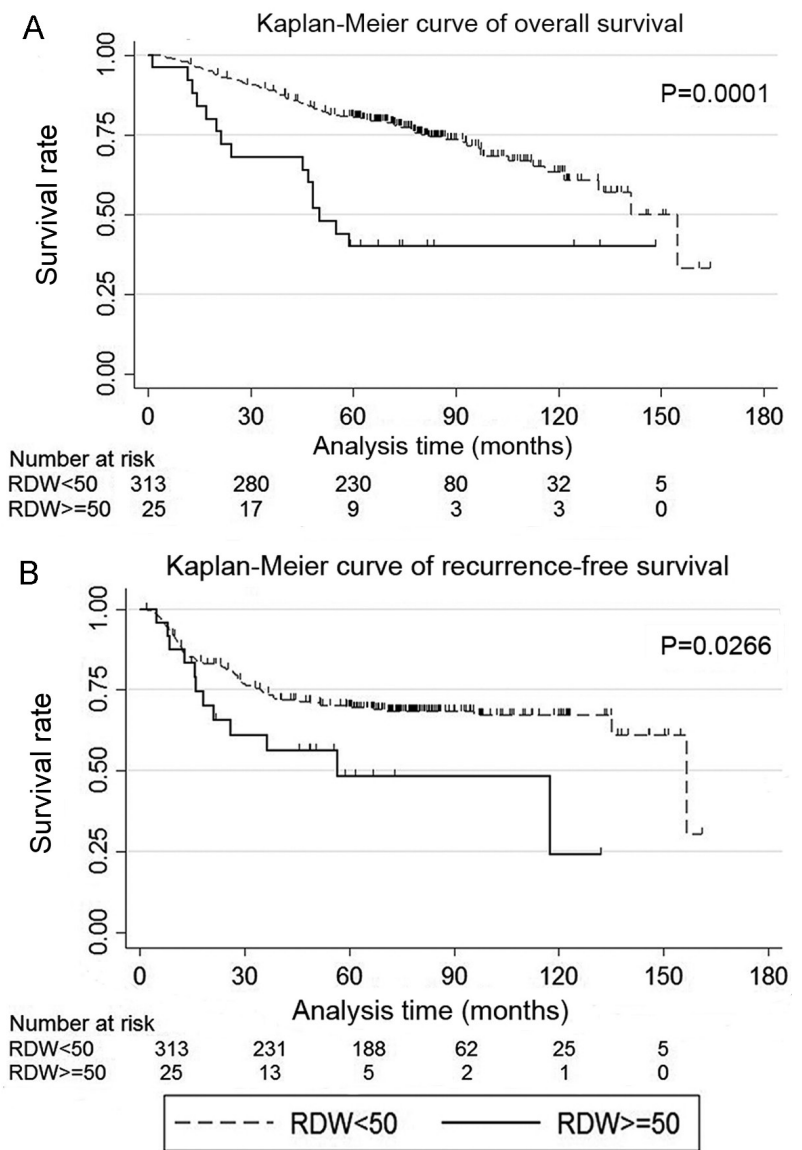

Figure 1. Kaplan-Meier curves of (A) overall and (B) recurrence-free survival for patients with non-small cell lung cancer, according to the RDW. RDW, red blood cell distribution width.

inhibiting iron metabolism and the response to erythropoietin, leading to an increase in RDW (14). Recently, elevated RDW levels were found to be associated with adverse outcomes in patients with heart failure, sepsis, breast cancer, esophageal carcinoma and lung cancer $(3,4,6,7,15)$.

To date, eight studies have investigated the role of RDW in lung cancer (Table IV) (15-22). All studies but one reported that high RDW was associated with poor prognosis in patients with lung cancer. The exact mechanism of how high RDW affects the prognosis of patients with lung cancer has not been elucidated. In previous studies, surgical treatment for NSCLC included sublobar resection (15,18-22); the novelty of the present study was that it investigated patients with NSCLC who had undergone lobectomy.

Surgical resection is considered as the main and best treatment option for early-stage NSCLC. Sublobar resection was previously considered as a palliative surgery for high-risk patients with NSCLC. Several recent studies have demonstrated comparable recurrence and survival rates between sublobar resection and lobectomy for early-stage NSCLC, and the optimal strategy for early-stage NSCLC remains a subject of debate $(9,10)$. Lobectomy remains the standard choice for NSCLC, and has been shown to minimize the risk of recurrence and optimize the chances for long-term survival. However, the overall survival range achieved by lobectomy is $73-90 \%$ (23), indicating that not all patients can benefit from surgery. Cancer type, systemic inflammation and abnormal 
Table II. Univariate and multivariate Cox proportional hazard models for overall survival.

A, Univariate analysis

\begin{tabular}{|c|c|c|c|}
\hline Variables & Hazard ratio & $95 \% \mathrm{CI}$ & P-value \\
\hline RDW & 2.95 & $1.70-5.12$ & $<0.001$ \\
\hline Age & 1.74 & $1.16-2.60$ & 0.007 \\
\hline Sex & 0.61 & $0.40-0.95$ & 0.027 \\
\hline Body mass index & 1.05 & $0.71-1.55$ & 0.809 \\
\hline Brinkman index & 1.37 & $0.91-2.04$ & 0.128 \\
\hline Anemia & 1.09 & $0.58-2.04$ & 0.787 \\
\hline Carcinoembryonic antigen & 1.91 & $1.28-2.84$ & 0.001 \\
\hline Diabetes mellitus & 0.87 & $0.49-1.53$ & 0.628 \\
\hline Heart disease & 1.89 & $1.01-3.55$ & 0.047 \\
\hline History of malignancy & 1.66 & $1.04-2.65$ & 0.034 \\
\hline Charlson Comorbidity Index & 2.17 & $1.40-3.37$ & $<0.001$ \\
\hline$\% \mathrm{VC}$ & 2.78 & $1.13-6.87$ & 0.027 \\
\hline FEV1.0\% & 1.47 & $0.96-2.24$ & 0.078 \\
\hline SUVmax & 2.50 & $1.52-4.13$ & $<0.001$ \\
\hline \multicolumn{4}{|l|}{ cTNM } \\
\hline I & 1 & & \\
\hline II & 2.22 & $1.35-3.63$ & 0.002 \\
\hline III & 5.50 & $2.00-15.11$ & 0.001 \\
\hline \multicolumn{4}{|l|}{ Pathological subtype } \\
\hline Adenocarcinoma & 1 & $0.56-1.90$ & 0.918 \\
\hline Squamous cell carcinoma & 1.03 & $1.10-3.35$ & 0.022 \\
\hline Others & 1.92 & & \\
\hline
\end{tabular}

B, Multivariate analysis

\begin{tabular}{lccr}
\hline Variables & Hazard ratio & 95\% CI & P-value \\
\hline RDW & 2.29 & $1.3-4.01$ & 0.004 \\
Carcinoembryonic antigen & 1.89 & $1.26-2.84$ & 0.002 \\
Charlson Comorbidity Index & 2.28 & $1.26-2.84$ & $<0.001$ \\
SUVmax & 1.98 & $1.19-3.3$ & 0.009 \\
cTNM & & & \\
I & 1 & $1.03-2.81$ & 0.039 \\
II & 1.70 & $2.51-19.8$ & $<0.001$ \\
III & 7.05 & & \\
\hline
\end{tabular}

Multivariate analysis was conducted with the stepwise backward elimination method with a probability level of 0.15 . Covariates with $\mathrm{P}<0.05$ in the univariate analysis were entered into the Cox model. RDW, red blood cell distribution width; VC, vital capacity; FEV1.0, forced expiratory volume in $1 \mathrm{sec}$; SUVmax, maximum standardized uptake value; cTNM, clinical TNM stage.

metabolism may be associated with poor prognosis, even at the same cancer stage.

Cachexia is defined as a complex metabolic syndrome with progressive weight loss and depletion of host reserves of adipose tissue and skeletal muscle (24). Cachexia may be clinically associated with malignancy and is reported to be associated with $>20 \%$ of cancer-related fatalities (25). Inflammation plays a crucial role in the pathogenesis of cachexia, leading to an imbalance between pro- and anti-inflammatory cytokines, concomitant body weight loss and sarcopenia. Sarcopenia is primarily associated with the elderly, and there are considerable overlaps between cachexia and sarcopenia in individuals aged $\geq 66$ years (26); the study by Ichinose et al (19) suggested that older patients had a worse prognosis.

Cachexia has the following diagnostic criteria: Weight loss of $>5 \%$, or any significant weight loss $(>2 \%)$ in the presence of either a low BMI or a low skeletal muscle mass. Cachexia is considered to consist of a spectrum of abnormalities that may progress through the following phases: Pre-cachexia, cachexia and refractory cachexia. Pre-cachexia is a condition 
Table III. Univariate and multivariate Cox proportional hazard models for recurrence-free survival.

A, Univariate analysis

\begin{tabular}{|c|c|c|c|}
\hline Variables & Hazard ratio & $95 \% \mathrm{CI}$ & P-value \\
\hline RDW & 1.95 & $1.07-3.56$ & 0.03 \\
\hline Age & 0.96 & $0.66-1.40$ & 0.852 \\
\hline Sex & 0.99 & $0.68-1.46$ & 0.97 \\
\hline Body mass index & 0.92 & $0.63-1.34$ & 0.658 \\
\hline Brinkman index & 1.00 & $0.69-1.46$ & 0.99 \\
\hline Anemia & 0.78 & $0.41-1.50$ & 0.463 \\
\hline Carcinoembryonic antigen & 1.99 & $1.36-2.90$ & $<0.001$ \\
\hline Diabetes mellitus & 1.00 & $0.60-1.68$ & 0.997 \\
\hline Heart disease & 1.63 & $0.87-3.04$ & 0.125 \\
\hline History of malignancy & 1.11 & $0.67-1.82$ & 0.683 \\
\hline Charlson Comorbidity Index & 0.87 & $0.52-1.47$ & 0.608 \\
\hline$\% \mathrm{VC}$ & 1.64 & $0.60-4.45$ & 0.334 \\
\hline FEV1.0\% & 1.00 & $0.64-1.55$ & 1 \\
\hline SUVmax & 2.06 & $1.32-3.20$ & 0.001 \\
\hline \multicolumn{4}{|l|}{ cTNM } \\
\hline $\mathrm{I}$ & 1 & & \\
\hline II & 2.65 & $1.68-4.19$ & $<0.001$ \\
\hline III & 4.76 & $1.74-13.04$ & 0.002 \\
\hline \multicolumn{4}{|l|}{ Pathological subtype } \\
\hline Adenocarcinoma & 1 & $0.29-1.16$ & 0.125 \\
\hline Squamous cell carcinoma & 0.58 & $0.80-2.47$ & 0.237 \\
\hline Others & 1.41 & & \\
\hline
\end{tabular}

B, Multivariate analysis

\begin{tabular}{lccc}
\hline Variables & Hazard ratio & $95 \%$ CI & P-value \\
\hline Carcinoembryonic antigen & 1.90 & $1.30-2.79$ & 0.001 \\
SUVmax & 1.73 & $1.11-2.71$ & 0.017 \\
cTNM & & & \\
I & 1 & $1.42-3.57$ & 0.035 \\
II & 2.25 & $2.06-16.0$ & 0.001 \\
III & 5.74 & & \\
\hline
\end{tabular}

Multivariate analysis was conducted with the stepwise backward elimination method with a probability level of 0.15 . Covariates with $\mathrm{P}<0.05$ in the univariate analysis were entered into the Cox model. RDW, red blood cell distribution width; VC, vital capacity; FEV1.0, forced expiratory volume in $1 \mathrm{sec}$; SUVmax, maximum standardized uptake value; cTNM, clinical TNM stage.

with early clinical and metabolic signs, such as anorexia and inflammation, but without substantial weight loss. On the other hand, refractory cachexia may result from advanced cancer, or a rapidly progressive cancer unresponsive to anticancer treatment. This is associated with active catabolism and characterized by a low performance status and a life expectancy of $<3$ months (24).

Cachexia may occur in the early stages of cancer, and even with the same tumor type and burden, variations in cachexia may be associated with host genotype, cancer stage, as well as the presence of inflammation and malnutrition (27).
Argilés et al (28) reported that 50-80\% of patients with cancer experience cachexia. Pre-cachexia in patients with NSCLC is associated with a decreased exercise capacity, without changes in body composition, despite systemic inflammation $(29,30)$. In addition, anabolic resistance appears early in patients with cancer and pre-cachexia without any signs of malnutrition (29,30). A high RDW may reflect the inflammation and malnutrition associated with cachexia, and may be valuable for detecting early stages of this condition. One possible explanation for the differences in survival between patients with high and low RDW may be variations in the severity of cachexia. 
Table IV. Review of the association between RDW and overall survival in lung cancer.

\begin{tabular}{|c|c|c|c|c|c|}
\hline Study, year & $\begin{array}{l}\text { Number } \\
\text { of patients }\end{array}$ & $\begin{array}{l}\text { Hazard ratio } \\
\text { of high RDW }\end{array}$ & $95 \% \mathrm{CI}$ & Other variables in the estimated model & (Refs.) \\
\hline Toyokawa et al, 2019 & 273 & 2.44 & $1.28-4.49$ & $\begin{array}{l}\text { Sex, PS, BMI, smoking history, CEA, } \\
\text { Surgical procedure, pathological stage, } \\
\text { histology, CONUT score, hemoglobin }\end{array}$ & (15) \\
\hline Bozkaya et al, 2019 & 153 & $1.607^{\mathrm{a}}$ & $1.041-2.480$ & $\begin{array}{l}\text { Age, PS, weight loss, GPS, NLR, } \\
\text { number of metastatic sites }\end{array}$ & (16) \\
\hline Kiriu et al, 2019 & 47 & 3.04 & $1.02-7.65$ & NLR, smoking history, age, sex, PS & (17) \\
\hline Kobayashi et al, 2019 & 166 & $2.8^{\mathrm{b}}$ & $1.2-6.5$ & Sex, CEA, GPS, NLR, ALI & (18) \\
\hline Ichinose et al, 2016 & $275^{c}$ & 2.1 & $1.3-3.6$ & Sex, $\mathrm{T}$ factor, $\mathrm{N}$ factor, sublobar resection & (19) \\
\hline Kos et al, 2016 & 146 & NS & Not listed & Age, sex, PS, stage, histology, treatment & (20) \\
\hline Koma et al, 2013 & 332 & 2.15 & $1.04-4.46$ & $\begin{array}{l}\text { Stage, PS, other disease, treatment, } \\
\text { albumin, CRP }\end{array}$ & (21) \\
\hline Warwick et al, 2014 & 917 & 1.54 & $1.25-1.89$ & $\begin{array}{l}\text { Age, alcohol intake, emphysema, } \\
\text { squamous carcinoma, predicted } \\
\text { postoperative FEV1, T stage, } N \text { stage }\end{array}$ & (22) \\
\hline
\end{tabular}

${ }^{a}$ Hemoglobin/RDW ratio. ${ }^{b}$ Univariate analysis. ${ }^{\mathrm{c}} \mathrm{Age}>75$ years. RDW, red blood cell distribution width; PS, performance status; BMI, body mass index; CEA, carcinoembryonic antigen; CONUT score, controlling nutritional status score; GPS, Glasgow prognostic score; NLR, neutrophil-to-lymphocyte ratio; ALI, advanced lungcancer inflammation index; NS, not significant; CRP, C-reactive protein; FEV1, forced expiratory volume in $1 \mathrm{sec}$.

Thus far, inflammation-based prognostic systems, such as neutrophil-to-lymphocyte ratio, platelet-to-lymphocyte ratio and Glasgow prognostic score (GPS), have been reported in the field of clinical oncology (31-33). The former two are based on two cellular components, whereas the latter is based on two protein components. None of these indicators is superior to the others, and each plays a complementary role. GPS has been shown to predict the source of cachexia, as well as its prognosis (34). Similar to GPS, RDW is an indicator that is easy to measure and may be used to evaluate the degree of cachexia.

The present retrospective study had several limitations. First, it was conducted by a single institution and, therefore, it had a high risk of bias in terms of data selection and analysis. Second, the sample size was relatively small, and further data accumulation is required. Third, due to the lack of body weight loss data, we were unable to determine the stage of cachexia. Further studies are required to investigate body weight loss. Fourth, the day of blood sample collection differed among patients. It is possible that variations in RDW were not assessed during the time period from the day of collection to the day of surgery. Finally, no repeat measurements of RDW were performed, which may have led to novel discoveries.

In conclusion, it was herein demonstrated that high preoperative RDW is an independent prognostic factor for overall survival in patients with NSCLC. Measuring RDW is simple and cost-effective. Cachexia may occur at any stage of cancer, mainly due to inflammation, even when there are no changes in body composition, and it is also associated with sarcopenia and malnutrition. Elevated RDW may indicate the degree of cachexia progression; therefore, it may be useful as a surrogate marker for predicting the survival of patients with NSCLC undergoing standard lung lobectomy.

\section{Acknowledgements}

Not applicable.

\section{Funding}

No funding was received.

\section{Availability of data and materials}

The datasets used and/or analyzed during the present study are available from the corresponding author on reasonable request.

\section{Authors' contributions}

HM wrote the manuscript. HM and YT collected the data. NM, TU, TS and HH collected important background information, prepared the preliminary manuscript and helped with preliminary data collection. TM made substantial contributions to the study conception and design, and gave final approval for this manuscript to be published. All the authors have read and approved the final manuscript.

\section{Ethics approval and consent to participate}

Prior to study initiation, the Research Review Board of Kansai Medical University Hospital examined and approved the research protocol (approval no. 2019313). The study was conducted in accordance with the principles outlined in the Declaration of Helsinki. The need for patient informed consent was waived, provided that the patient data were anonymized. 


\section{Patient consent for publication}

Not applicable.

\section{Competing interests}

The authors declare that they have no competing interests.

\section{References}

1. Walters JG and Garrity PF: RDW-SD and RDW-CV: Their relationship to RBC distribution curves and anisocytosis. Sysmex J Int 3: 40-45, 1993

2. Sultana GS, Haque SA, Sultana T and Ahmed AN: Value of red cell distribution width (RDW) and RBC indices in the detection of iron deficiency anemia. Mymensingh Med J 22: 370-376, 2013

3. Felker GM, Allen LA, Pocock SJ, Shaw LK, McMurray JJ, Pfeffer MA, Swedberg K, Wang D, Yusuf S, Michelson EL, et al: Red cell distribution width as a novel prognostic marker in heart failure: Data from the charm program and the duke databank J Am Coll Cardiol 50: 40-47, 2007.

4. Jo YH, Kim K, Lee JH, Kang C, Kim T, Park HM, Kang KW, Kim J and Rhee JE: Red cell distribution width is a prognostic factor in severe sepsis and septic shock. Am J Emerg Med 31: 545-548, 2013

5. Ozsu S, Ozcelik N, Oztuna F and Ozlu T: Prognostic value of red cell distribution width in patients with sarcoidosis. Clin Respir J 9: 34-38, 2015.

6. Bilgin B, Sendur MA, Hizal M, Dede DS, Akinci MB, Kandil SU, Yaman S, Yalçin A, Kiliç M and Yalçin B: Prognostic effect of red cell distribution width-to-platelet ratio in colorectal cancer according to tumor stage and localization. J Cancer Res Ther 15: 54-60, 2019.

7. Huang DP, Ma RM and Xiang YQ: Utility of red cell distribution width as a prognostic factor in young breast cancer patients Medicine (Baltimore) 95: e3430, 2016.

8. Wan GX, Chen P, Cai XJ, Li LJ, Yu XJ, Pan DF, Wang XH, Wang XB and Cao FJ: Elevated red cell distribution width contributes to a poor prognosis in patients with esophageal carcinoma. Clin Chim Acta 452: 199-203, 2016.

9. Winckelmans T, Decaluwé H, De Leyn P and Van Raemdonck D: Segmentectomy or lobectomy for early-stage non-small-cell lung cancer: A systematic review and meta-analysis. Eur J Cardiothorac Surg 57: 1051-1060, 2020.

10. Ijsseldijk MA, Shoni M, Siegert C, Seegers J, van Engelenburg AK, Tsai TC, Lebenthal A, and Ten Broek RP: Oncological outcomes of lobar resection, segmentectomy, and wedge resection for T1a non-small-cell lung carcinoma: A systematic review and meta-analysis. Semin Thorac Cardiovasc Surg 32: 582-590, 2020.

11. Brierley JD, Gospodarowicz MK and Wittekind CH (eds) TNM classification of malignant tumours. 8th edition. John Wiley \& Sons, Chichester, West Sussex, pp106-112, 2017.

12. Travis WD, Brambilla E, Muller-Hermelink HK and Harris CC: Pathology and genetics of tumours of the lung, pleura, thymus and heart. In: World Health Organization Classification of Tumours Kleihues P and Sobin LH (eds). Lyon, International Agency for Research on Cancer Press, pp9-124, 2004.

13. Kanda Y: Investigation of the freely available easy-to-use software 'EZR' for medical statistics. Bone Marrow Transplant 48 452-458, 2013

14. Förhécz Z, Gombos T, Borgulya G, Pozsonyi Z, Prohászka Z and Jánoskuti L: Red cell distribution width in heart failure: Prediction of clinical events and relationship with markers of ineffective erythropoiesis, inflammation, renal function, and nutritional state. Am Heart J 158: 659-666, 2009.

15. Toyokawa G, Shoji F, Yamazaki K, Shimokawa M and Takeo S: Significance of the red blood cell distribution width in resected pathologic stage I nonsmall cell lung cancer. Semin Thorac Cardiovasc Surg 32: 1036-1045, 2020.

16. Bozkaya Y, Kurt B and Gürler F: A prognostic parameter in advanced non-small cell lung cancer: The ratio of hemoglobin-to-red cell distribution width. Int J Clin Oncol 24: 798-806, 2019.
17. Kiriu T, Yamamoto M, Nagano T, Koyama K, Katsurada M, Tamura D, Nakata K, Tachihara M, Kobayashi K and Nishimura Y: Prognostic value of red blood cell distribution width in non-small cell lung cancer treated with anti-programmed cell death-1 antibody. In Vivo 33: 213-220, 2019.

18. Kobayashi S, Karube Y, Inoue T, Araki O, Maeda S, Matsumura Y and Chida M: Advanced lung cancer inflammation index predicts outcomes of patients with pathological stage IA lung adenocarcinoma following surgical resection. Ann Thorac Cardiovase Surg 25: 87-94, 2019.

19. Ichinose J, Murakawa T, Kawashima M, Nagayama K, Nitadori JI, Anraku M and Nakajima J: Prognostic significance of red cell distribution width in elderly patients undergoing resection for non-small cell lung cancer. J Thorac Dis 8: 3658-3666, 2016.

20. Kos M, Hocazade C, Kos FT, Uncu D, Karakas E, Dogan M, Uncu HG, Ozdemir N and Zengin N: Evaluation of the effects of red blood cell distribution width on survival in lung cancer patients. Contemp Oncol (Pozn) 20: 153-157, 2016.

21. Koma Y, Onishi A, Matsuoka H, Oda N, Yokota N, Matsumoto Y, Koyama M, Okada N, Nakashima N, Masuya D, et al: Increased red blood cell distribution width associates with cancer stage and prognosis in patients with lung cancer. PLoS One 8: e80240, 2013.

22. Warwick R, Mediratta N, Shackcloth M, Shaw M, McShane J and Poullis M: Preoperative red cell distribution width in patients undergoing pulmonary resections for non-small-cell lung cancer. Eur J Cardio Thorac Surg 45: 108-113, 2014.

23. Goldstraw P, Chansky K, Crowley J, Rami-Porta R, Asamura H, Eberhardt WE, Nicholson AG, Groome P, Mitchell A, Bolejack V, et al: The IASLC lung cancer staging project: Proposals for revision of the TNM stage groupings in the forthcoming (eighth) edition of the TNM classification for lung cancer. J Thorac Oncol 11: 39-51, 2016.

24. Fearon K, Strasser F, Anker SD, Bosaeus I, BrueraE, Fainsinger RL, Jatoi A, Loprinzi C, MacDonald N, Mantovani G, et al: Definition and classification of cancer cachexia: An international consensus. Lancet Oncol 12: 489-495, 2011.

25. Tisdale MJ: Cachexia in cancer patients. Nat Rev Cancer 2 862-871, 2002.

26. Cruz-Jentoft AJ, Bahat G, Bauer J, Boirie Y, Bruyère $\mathrm{O}$, Cederholm T, Cooper C, Landi F, Rolland Y, Sayer AA, et al: Sarcopenia: Revised European consensus on definition and diagnosis. Age Ageing 48: 601, 2019.

27. Fearon KC, Glass DJ and Guttridge DC: Cancer cachexia: Mediators, signaling, and metabolic pathways. Cell Metab 16: 153-166, 2012.

28. Argilés JM, Busquets S, Stemmler B and López-Soriano FJ: Cancer cachexia: Understanding the molecular basis. Nat Rev Cancer 14: 754-762, 2014

29. Op den Kamp CM, Langen RC, Minnaard R, Kelders MC, Snepvangers FJ, Hesselink MK, Dingemans AC and Schols AM: Pre-cachexia in patients with stages I-III non-small cell lung cancer: Systemic inflammation and functional impairment without activation of skeletal muscle ubiquitin proteasome system. Lung Cancer 76: 112-117, 2012.

30. Deutz NE, Safar A, Schutzler S, Memelink R, Ferrando A, Spencer H, van Helvoort A and Wolfe RR: Muscle protein synthesis in cancer patients can be stimulated with a specially formulated medical food. Clin Nutr 30: 759-768, 2011.

31. Templeton AJ, McNamara MG, Šeruga B, Vera-Badillo FE, Aneja P, Ocaña A, Leibowitz-Amit R, Sonpavde G, Knox JJ, Tran B, et al: Prognostic role of neutrophil-to-lymphocyte ratio in solid tumors: A systematic review and meta-analysis. J Natl Cancer Inst 106: dju124, 2014.

32. Łochowski M, Łochowska B, Zawadzka I, Cieślik-Wolski B, Kozik D and Kozak J: Prognostic value of neutrophil-to-lymphocyte, platelet-to-lymphocyte and lymphocyte-to-monocyte ratio ratios in patients operated on due to non-small cell lung cancer. J Thorac Dis 11: 3377-3384, 2019.

33. Forrest LM, McMillan DC, McArdle CS, Angerson WJ and Dunlop DJ: Evaluation of cumulative prognostic scores based on the systemic inflammatory response in patients with inoperable non-small-cell lung cancer. Br J Cancer 89: 1028-1030, 2003.

34. McMillan DC: Systemic inflammation, nutritional status and survival in patients with cancer. Curr Opin Clin Nutr Metab Care 12: 223-226, 2009

This work is licensed under a Creative Commons Attribution-NonCommercial-NoDerivatives 4.0 International (CC BY-NC-ND 4.0) License. 